\title{
Mechanical properties of roller compacted concrete containing recycled concrete aggregate
}

\author{
Hojjat Hosseinnezhad (Main and Corresponding Author) \\ Department of Civil Engineering, Eng. Faculty, Ege University, \\ Bornova-izzmir 35040 (Turkey) \\ hoji.us@gmail.com \\ https://orcid.org/0000-0002-9846-2435
}

\section{Daniel Hatungimana}

Department of civil engineering, Burundi University, Bujumbura 1550 (Burundi)

hatungimana.daniel@gmail.com

https://orcid.org/0000-0001-7564-0756

\section{Șemsi Yazıcı}

Department of Civil Engineering, Eng. Faculty, Ege University, Bornova-İzmir 35040 (Turkey)

semsi.yazici@ege.edu.tr

https://orcid.org/0000-0002-2733-0515

\section{Kambiz Ramyar}

Department of Civil Engineering, Eng. Faculty, Ege University, Bornova-İzmir 35040 (Turkey)

kambiz.ramyar@ege.edu.tr

https://orcid.org/0000-0003-2200-2691

Manuscript Code: 16167

Date of Acceptance/Reception: 29.06.2021/24.06.2020

DOI: 10.7764/RDLC.20.2.277

\begin{abstract}
The compressive strength, splitting tensile strength, pulse velocity and drop weight impact resistance of roller compacted concrete (RCC) mixtures containing recycled concrete aggregate (RCA) were investigated. The cement contents of the RCC mixtures were chosen as 150,200 and $250 \mathrm{~kg} / \mathrm{m}^{3}$. In addition to the control mixtures containing no RCA, 25, 50, 75 and $100 \mathrm{wt} \%$ of the crushed limestone aggregate was replaced with RCA. In this way, 15 RCC mixtures were prepared. The water content of RCC mixtures was determined by the maximum density method. The results showed that increasing the amount of recycled aggregate decreased the mechanical properties of the concrete. However, up to $25 \%$ replacement level, recycled aggregate had not a significant detrimental effect on the properties of RCC. Besides, the detrimental effect of RCA substitution was more pronounced in leaner mixtures and reduced by increasing the cement content of the RCC.
\end{abstract}

Keywords: roller compacted concrete, recycled aggregate, cement dosages, optimum water content, mechanical properties.

In recent years, urban renewal programs in Turkey implemented huge concrete waste. Using these wastes as recycled aggregate in roller compacted concrete (RCC) is one of the possibilities to reduce the difficulties arises from their deposition. As a result of the demolition of old structures, large volume concrete waste is emerging and large field is needed to store them. Due to the increase of environmental awareness, the concrete waste storage is a major problem in large cities of Turkey. One of the main purposes in the protection of natural life is the recovery and utilization of waste in a way that reduces the use of natural resources. Metal-based construction wastes are easily distinguished and recycled. On the other hand, concrete wastes are poured into agricultural areas or storage areas as rubble and stored. It is possible to separate these wastes from other construction wastes and to be broken into aggregate. Re-use of this type of recycled concrete waste aggregate in concrete production will reduce the environmental damage of these wastes and the consumption of 
natural aggregate. The decrease or depletion of natural resources over time, the distance of existing resources from their usage areas increases the interest in recycling of construction waste. The fact that most of the buildings that have been demolished or will be demolished during the urban transformation process are reinforced concrete, will allow the waste to be obtained from these to be used instead of aggregate in concrete. Therefore, it is also very important to encourage the use of such recycled concrete aggregates in the production of low strength concrete like RCCs to use them in road concrete.

The rapid urbanization and increased population made cause rapid consumption of natural resources and reduce their sustainability. Therefore, waste materials recycling is very important in terms of the preservation of the natural resources. Now a days, in order to reduce the above mentioned distress waste aggregates recycled from old concrete or old asphalt concrete mixtures are used in concrete in some countries (Gürer, 2004). The effect of recycled asphalt concrete aggregate and waste rubber particles on the properties of RCC have been studied by many researchers (Courard et. al., 2010; Fakhri, 2016; LaHucik et al. 2017; Meddah et. al., 2014; Modarres et. al., 2014; Settari et. al., 2015). Besides, there are various studies on the effect of coarse recycled concrete aggregate (RCA) on the properties of conventional portland cement concrete. It was found that replacement of natural coarse aggregate with RCA at levels up to $30 \mathrm{wt} \%$ had no significant detrimental effect on the strength of concrete. However, beyond $30 \mathrm{wt} \%$ replacement level, a considerable reduction in the strength of RCA-bearing mixtures, compared to that of the control mixture, was reported (Peng et. al., 2013; Muscalu et. al., 2011; Rao et. al., 2011; Etxeberria et. al., 2007; Paul et. al., 2013; Sonawane et. al., 2013).

Debieb et. al. (2009), produced RCA from laboratory made $40 \mathrm{MPa}$ strength concrete containing crushed limestone aggregate having $20 \mathrm{~mm}$ maximum size $\left(D_{\max }\right)$ and an average specific gravity around 2.7 . The RCA thus produced, had a 20 $\mathrm{mm} \mathrm{D} \mathrm{D}_{\max }$, an average specific gravity of 2.3 and absorption capacity of $9.2 \%, 4.9 \%$ and $6 \%$ for $0 / 4,4 / 14$ and $14 / 20 \mathrm{~mm}$, size fractions, respectively. RCC mixtures having a cement content of $250 \mathrm{~kg} / \mathrm{m}^{3}$ were prepared either with natural crushed limestone aggregate or $100 \%$ replacement of natural aggregate with RCA. The w/c ratio of the control mixture $(0.38)$, was somewhat higher than that of the RCA-bearing mixture (0.32). In spite of having a lower w/c ratio, RCA-containing mixture showed $30 \%, 56 \%$ and $32 \%$ lower compressive strength, splitting tensile strength and modulus of elasticity, respectively, compared to those of the control mixture (Debieb et. al., 2009).

Lopez-Uceda et. al. (2016), investigated the mechanical properties of RCC containing RCA obtained from a construction and demolition waste plant. The RCA had an SSD density of $2.51 \mathrm{~g} / \mathrm{cm}^{3}$, water absorption of $4.69 \%$ and maximum particle size of $31.5 \mathrm{~mm}$. Four series of RCC mixtures having $110,175,250$ and $350 \mathrm{~kg} / \mathrm{m}^{3}$ cement contents were prepared. In addition to the control mixture containing no RCA, 50 and 100 vol\% of the coarse natural aggregate was replaced with coarse RCA. For a given workability, the water requirement of RCA-bearing mixtures was found to increase by increasing RCA substitution level, reaching to around $122 \%$ that of the control mixture. Depending on the cement content, the 28 -day compressive strength of RCC mixtures was found to be in the range of 5.4 to $34.5 \mathrm{MPa}$. The corresponding range for flexural strength was 1.0 to $5.4 \mathrm{MPa}$. The RCA-bearing mixtures were reported to have a higher rate of compressive strength development beyond 28 days than the corresponding control mixtures. Compared to that of the control mixtures, the average reduction in 28-day splitting tensile strength was in the range of $8-15 \%$ in 50\% RCA-bearing (RCA50) mixtures and $13-27 \%$ in $100 \%$ RCA-containing (RCA100) mixtures. The corresponding values for the reduction in 28 -day flexural strength were around $18 \%$ and $24 \%$, respectively; which were very close to the average reduction in 28-day elastic moduli values upon RCA substitution (19\% for RCA50 and $28 \%$ for RCA100 mixtures) (Lopez-Uceda et. al., 2016).

Jalilifar et. al. (2020) investigated the durability of concrete containing coarse recycled concrete aggregate as well as silicafume and natural zeolite. For this purpose, four series of RCC mixtures were prepared. In these mixtures $0 \%, 25 \%, 50 \%$, and 100 wt.\% of natural coarse aggregate (NCA's) were replaced with RCA. Besides, cement replaced with 5\%, 10\%, and 15 wt.\% silica fume or $10 \%, 20 \%$, and 30 wt. $\%$ of zeolite. The 28 -day compressive strength, water absorption by immersion, water suction, and rapid chloride ion penetration properties were investigated. The water absorption and water suction of the mixtures increased by increasing coarse RCA level. The RCC mixture containing $10 \%$ silica fume showed the highest compressive strength. Besides, RCC's incorporating natural zeolite had higher water absorption than that of silica fumebearing mixtures. The RCC mixture containing $25 \%$ RCA and $10 \%$ silica fume showed the lowest chloride ion penetration depth (Jalilifar et. al., 2020). 
In this study, the mechanical properties of 15 RCC mixtures containing 150,200 and $250 \mathrm{~kg} / \mathrm{m}^{3}$ cement as well as $25,50,75$ and $100 \%$ coarse recycled aggregate (replaced with crushed limestone coarse aggregate) were investigated.

\section{Materials}

In the experimental study, a CEM II/A-M (P-L) 42.5R cement was used. The chemical composition, physical properties and compressive strength of the cement are given in Table 1.

\begin{tabular}{cc} 
Table 1. Chemical composition, physical and mechanical properties of cement. (Self-Elaboration). \\
\hline Chemical composition & $(\%)$ \\
\hline $\mathrm{SiO}_{2}$ & 21.68 \\
$\mathrm{Al}_{2} \mathrm{O}_{3}$ & 6.43 \\
$\mathrm{Fe}_{2} \mathrm{O}_{3}$ & 2.43 \\
$\mathrm{CaO}$ & 57.99 \\
$\mathrm{MgO}$ & 1.36 \\
$\mathrm{Na}_{2} \mathrm{O}$ & 0.36 \\
$\mathrm{~K}_{2} \mathrm{O}$ & 1.08 \\
$\mathrm{SO}_{3}$ & 2.987 \\
Loss on ignition & 5.18 \\
$\mathrm{Cl}$ & 0.0095 \\
Insoluble residue & 7.83 \\
Free CaO & 0.83 \\
\hline Physical properties & $(\%)$ \\
\hline Specific gravity & 3.12 \\
Blaine specific surface (cm $\left.{ }^{2} / \mathrm{g}\right)$ & 4535 \\
Initial setting time (min.) & 175 \\
Final setting time (min.) & 225 \\
\hline Compressive strength (MPa) & $(\%)$ \\
\hline 1-day & 14.4 \\
2-day & 26.7 \\
7-day & 39.3 \\
28-day & 47.0 \\
\hline &
\end{tabular}

\section{Aggregate}

Two types of aggregates were used as coarse aggregate in this investigation. Crushed coarse limestone aggregate (CLA) was used in the control mixtures. In the test mixtures 25, 50, 75 and $100 \mathrm{wt} \%$ of the coarse CLA was replaced with coarse RCA. The fine aggregate in all of the mixtures was crushed limestone. The physical properties of CLA and RCA are shown in Table 2.

Table 2. Physical properties of coarse and fine aggregates. (Self-Elaboration).

\begin{tabular}{lccccccc}
\hline \multirow{2}{*}{ Properties of aggregates } & \multicolumn{3}{c}{ LCA } & & \multicolumn{2}{c}{ RCA } \\
\cline { 2 - 4 } \cline { 7 - 8 } & $0-5 \mathrm{~mm}$ & $5-15 \mathrm{~mm}$ & $15-25 \mathrm{~mm} n$ & & $5-15 \mathrm{~mm}$ & $15-25 \mathrm{~mm}$ \\
\hline Dry rodded unit weight $\left(\mathrm{kg} / \mathrm{m}^{3}\right)$ & 1889 & 1573 & 1548 & & 1368 & 1308 \\
Loose unit weight $\left(\mathrm{kg} / \mathrm{m}^{3}\right)$ & 1673 & 1480 & 1466 & & 1215 & 1196 \\
SSD balk specific gravity & 2.654 & 2.676 & 2.711 & & 2.446 & 2.44 \\
Water absorption capacity (\%) & 0.92 & 0.30 & 0.23 & & 4.88 & 5.04 \\
\hline
\end{tabular}

The RCA were prepared by crushing waste concrete laboratory specimens having compressive strengths in the range of 20$50 \mathrm{MPa}$ using a jaw crusher. The RCA was screened it into $5 / 15$ and $15 / 25 \mathrm{~mm}$ size fractions. Gradations of the combined CLA and RCA as well as the Fuller curve are shown in Figure 1. 
Figure 1. Gradation curve of CLA, RCA and Fuller curve. (Self-Elaboration).

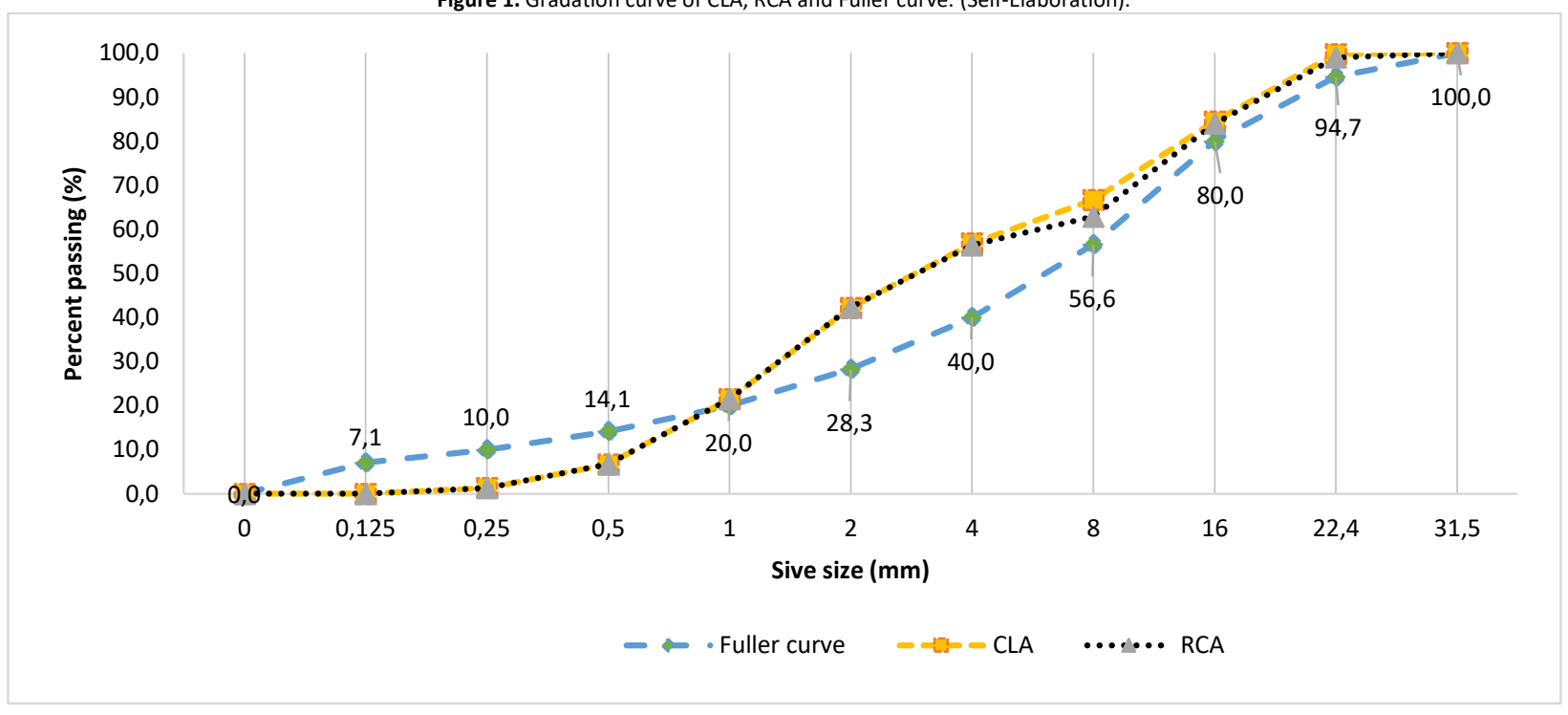

\section{Sample preparation}

The water content of RCC mixtures was determined by the maximum density method in accordance with ACl 207.5R.89 (ACl 207.5R.89, 1988). For this purpose, mixtures with at least four different water contents were prepared. The mixes were placed in three layers in 150/300 mm cylinder molds. Each layer was compacted for 15-20 seconds at around $20 \mathrm{~J}$ impact energy level using a $10.1 \mathrm{~kg}$ vibrating hummer equipped with a $5 \mathrm{~kg}$ tamping plate in accordance with ASTM C 1435. During the compaction of the top layer, an additional collar was used to obtain a smooth surface. The samples were designated by their cement content and RCA replacement level. For example, RCC150/100 indicates a mixture having $150 \mathrm{~kg} / \mathrm{m}^{3}$ cement, in which $100 \%$ of the CLA is replaced with RCA.

The wet unit weights of the compacted RCC samples were measured according to ASTM C 138 standard. The actual mix proportions, adjusted by taking into consideration the measured unit weights of fresh RCC mixtures are given in Table 3. A total of 15 RCC mixtures, including 3 control mixtures containing no RCA were prepared. The relation between dry unit weight and water content of RCC150/0 and RCC150/50 mixtures are shown in Figures 2 . The same procedure was applied to the other mixtures to determine their maximum dry density and optimum water content. The specimens were demolded after $24 \mathrm{~h}$ and cured in $22 \pm 2 \stackrel{\circ}{ } \mathrm{C}$ water until testing. As it can be observed from Table 3, the optimum water content and consequently the $\mathrm{w} / \mathrm{c}$ ratio of the mixtures increased by increasing RCA substitution level. Meanwhile, a gradual reduction occurred in the unit weight of RCC mixtures upon increasing RCA replacement level. The increasing in w/c ratio upon RCA inclusion became more pronounced by increasing cement content of the mixtures. 
Figure 2. Relation between dry unit weight and water content of $150 / 0$ and $150 / 50$ mixture. (Self-Elaboration).

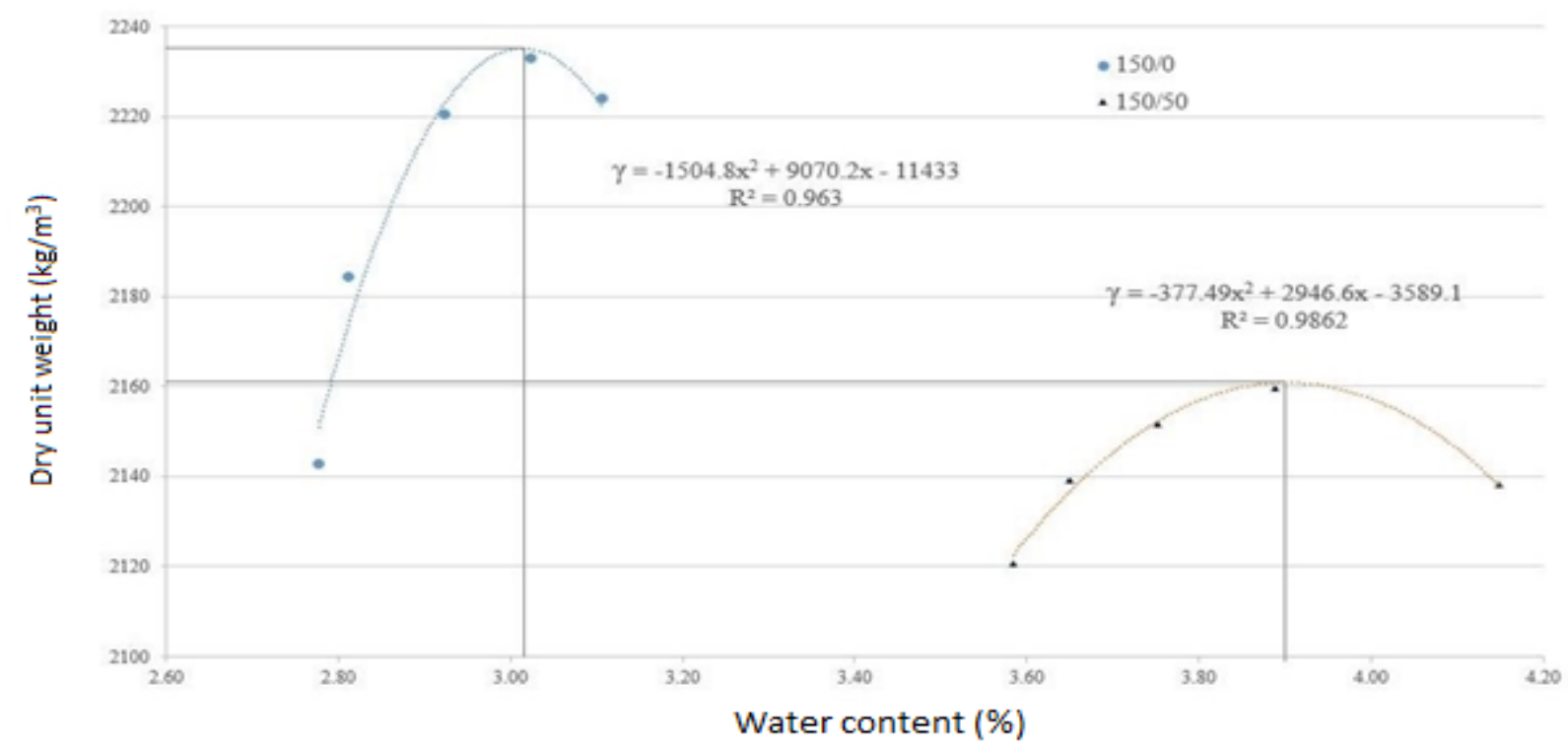

Table 3. The actual mix proportion of the RCC. (Self-Elaboration).

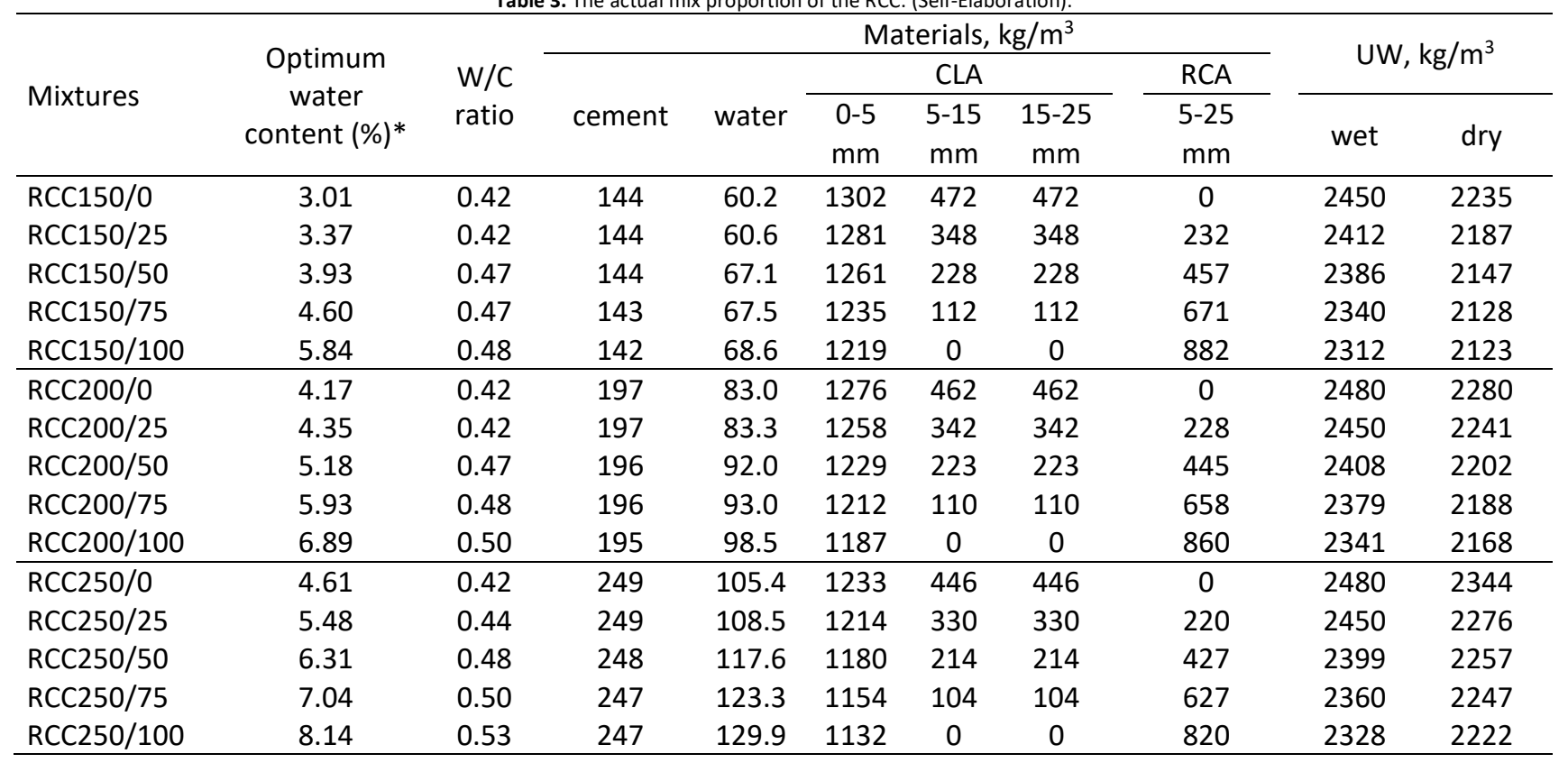

* percent by weight of the mixture.

\section{Test procedures}

The strength tests were applied on $150 \times 300$ mm cylinder specimens (EN 12390-3, 2010; EN 12390-6, 2010) and drop weight impact was applied on $150 \times 64 \mathrm{~mm}$ cylinder specimens, cut from $150 \times 300 \mathrm{~mm}$ cylinders (ACl Committee 544, 1988). The toughness values were calculated by dividing fracture energy $\left(\mathrm{mghN}_{\mathrm{f}}\right)$ of the specimens into the volume of specimens. Here, $\mathrm{m}$ is the dropping mass $(\mathrm{kg}), \mathrm{g}$ is gravitational acceleration $\left(9.8 \mathrm{~m} / \mathrm{s}^{2}\right)$, $\mathrm{h}$ is height $(\mathrm{m})$ from which the weight is dropped and $\mathrm{N}_{\mathrm{f}}$ is number of drops. The ultrasonic pulse velocity (UPV) values of 28-day, 90-day and 180 -day old $150 \times 300 \mathrm{~mm}$ cylinder specimens were determined in accordance with the ASTM C 597 standard (ASTM C 597, 2002). The dynamic elastic modulus of concrete was calculated by the following equation [Neville, 2010; Philleo, 1955): 


$$
E_{d}=\gamma c^{2} \frac{(1+u)(1-2 v)}{(1-v) \times 1000}
$$

where $E_{d}$ is the dynamic elastic modulus of concrete (GPa), $v$ the hardened concrete density $\left(\mathrm{kg} / \mathrm{m}^{3}\right), \mathrm{c}$ the UPV (km/s) and $v$ is the Poisson's ratio (assumed as 0.2 for all of the mixtures).

\section{Test results and discussion}

The compressive and split tensile strength as well as drop weight impact test results of RCC mixtures are given in Figure 3 and Figure 4 as well as in Table 4 . Besides, 95\% confidence intervals of relationship between 90-day compressive strength and dry unit weight of RCC mixtures are shown in Figure 5.

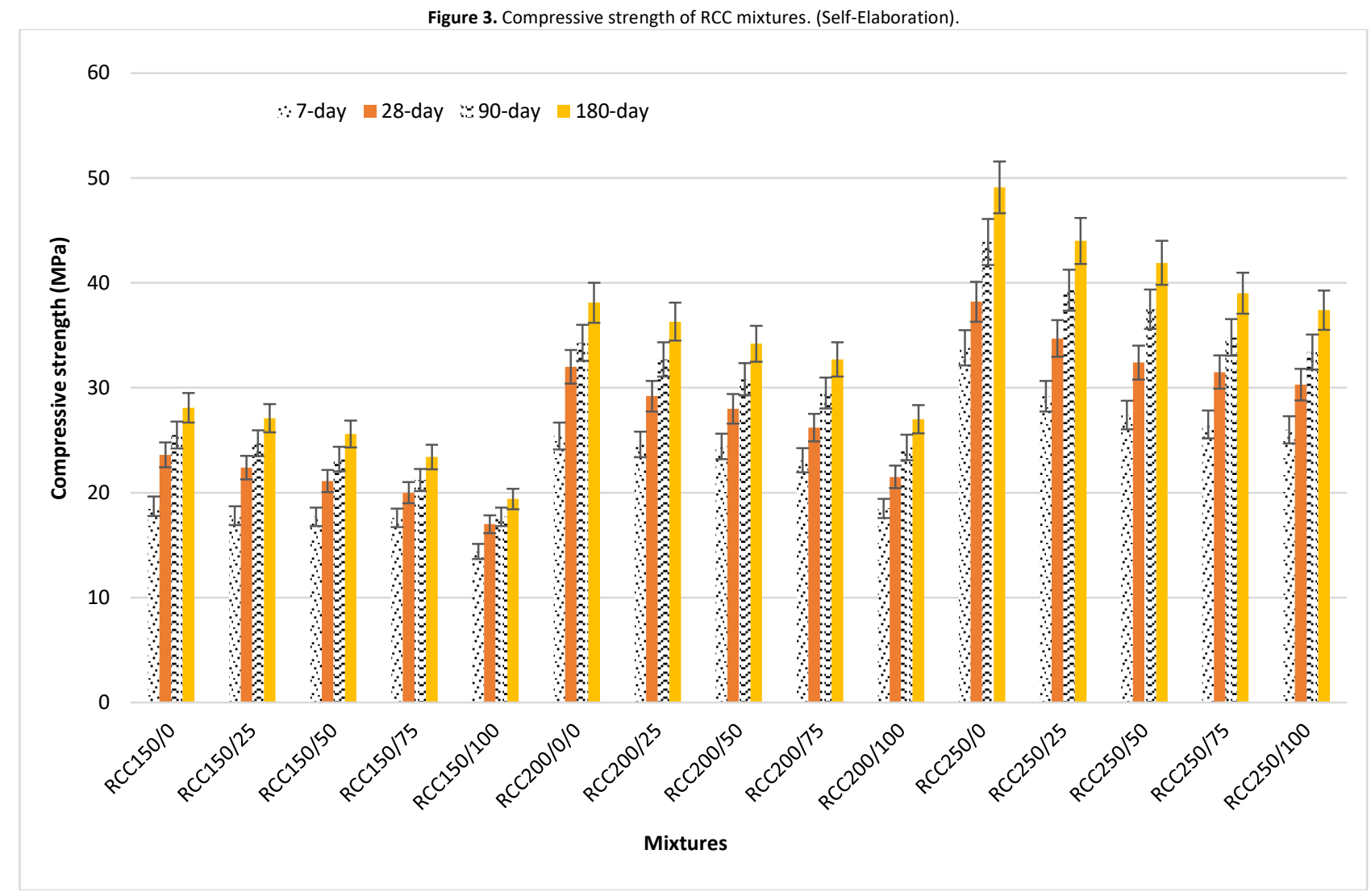






As it can be seen from the results, the minimum strength values at all ages in every cement content belongs to the mixtures that contain $100 \%$ RCA. Irrespective of cement content, the strength of RCC mixtures reduced upon replacement of CLA with RCA. The effect increased by increasing RCA replacement level. The reduction in strength upon RCA inclusion is in part due to the higher $w / c$ ratio of RCA-bearing mixtures and in part due to the presence of porous and weak old mortar adhered on the surface of RCA particles which may cause a weak bond strength between aggregate and new matrix compared to that of the LCA.

\begin{tabular}{|c|c|c|c|c|c|c|}
\hline \multirow[b]{2}{*}{ Mixture } & \multicolumn{2}{|c|}{ 28-day } & \multicolumn{2}{|c|}{ 90-day } & \multicolumn{2}{|c|}{ 180-day } \\
\hline & $\mathrm{N}_{f}$ & $\begin{array}{c}\text { Toughness } \\
\left(\mathrm{N} . \mathrm{mm} / \mathrm{mm}^{3}\right)\end{array}$ & $\mathrm{N}_{f}$ & $\begin{array}{c}\text { Toughness } \\
\left(\mathrm{N} . \mathrm{mm} / \mathrm{mm}^{3}\right)\end{array}$ & $\mathrm{N}_{f}$ & $\begin{array}{c}\text { Toughness } \\
\left(\mathrm{N} . \mathrm{mm} / \mathrm{mm}^{3}\right)\end{array}$ \\
\hline RCC150/0 & 25 & 0.44 & 28 & 0.49 & 29 & 0.51 \\
\hline RCC150/25 & 21 & 0.37 & 24 & 0.42 & 24 & 0.42 \\
\hline RCC150/50 & 21 & 0.37 & 23 & 0.40 & 23 & 0.40 \\
\hline RCC150/75 & 18 & 0.32 & 20 & 0.35 & 21 & 0.37 \\
\hline RCC150/100 & 15 & 0.26 & 17 & 0.30 & 18 & 0.32 \\
\hline RCC200/0/0 & 32 & 0.56 & 35 & 0.62 & 37 & 0.65 \\
\hline RCC200/25 & 31 & 0.54 & 33 & 0.58 & 36 & 0.63 \\
\hline RCC200/50 & 31 & 0.54 & 34 & 0.60 & 36 & 0.63 \\
\hline RCC200/75 & 26 & 0.46 & 29 & 0.51 & 30 & 0.53 \\
\hline RCC200/100 & 23 & 0.40 & 25 & 0.44 & 27 & 0.47 \\
\hline RCC250/0 & 51 & 0.90 & 55 & 0.97 & 57 & 1.00 \\
\hline RCC250/25 & 48 & 0.84 & 54 & 0.95 & 55 & 0.97 \\
\hline RCC250/50 & 46 & 0.81 & 49 & 0.86 & 51 & 0.90 \\
\hline RCC250/75 & 40 & 0.70 & 46 & 0.81 & 47 & 0.83 \\
\hline RCC250/100 & 37 & 0.65 & 39 & 0.69 & 41 & 0.72 \\
\hline
\end{tabular}






The splitting tensile strength / compressive strength ratio of RCC mixtures with $150 \mathrm{~kg} / \mathrm{m}^{3}$ cement content (i.e. RCC150/0, $\mathrm{RCC} 150 / 25, \mathrm{RCC} 150 / 50, \mathrm{RCC} 150 / 75$, and RCC150/100) were found to be $7.9 \%, 7.6 \%, 7.3 \%, 6.9 \%$ and $5.6 \%$. The corresponding values for the mixture containing 200 and $250 \mathrm{~kg} / \mathrm{m}^{3}$ cement were in the range of $10.4 \%$ to $8.9 \%$ and $10.7 \%$ to $9.7 \%$, respectively. The relationship between compressive strength, split tensile strength and toughness of the mixtures are plotted in Fig. 6, 7, 8 and 9. As it can be seen from the figures good correlations with coefficient of correlation $\left(R^{2}\right)$ values ranging from 0.92 to 0.96 were found between compressive strength, splitting tensile strength and toughness of the RCC mixtures.

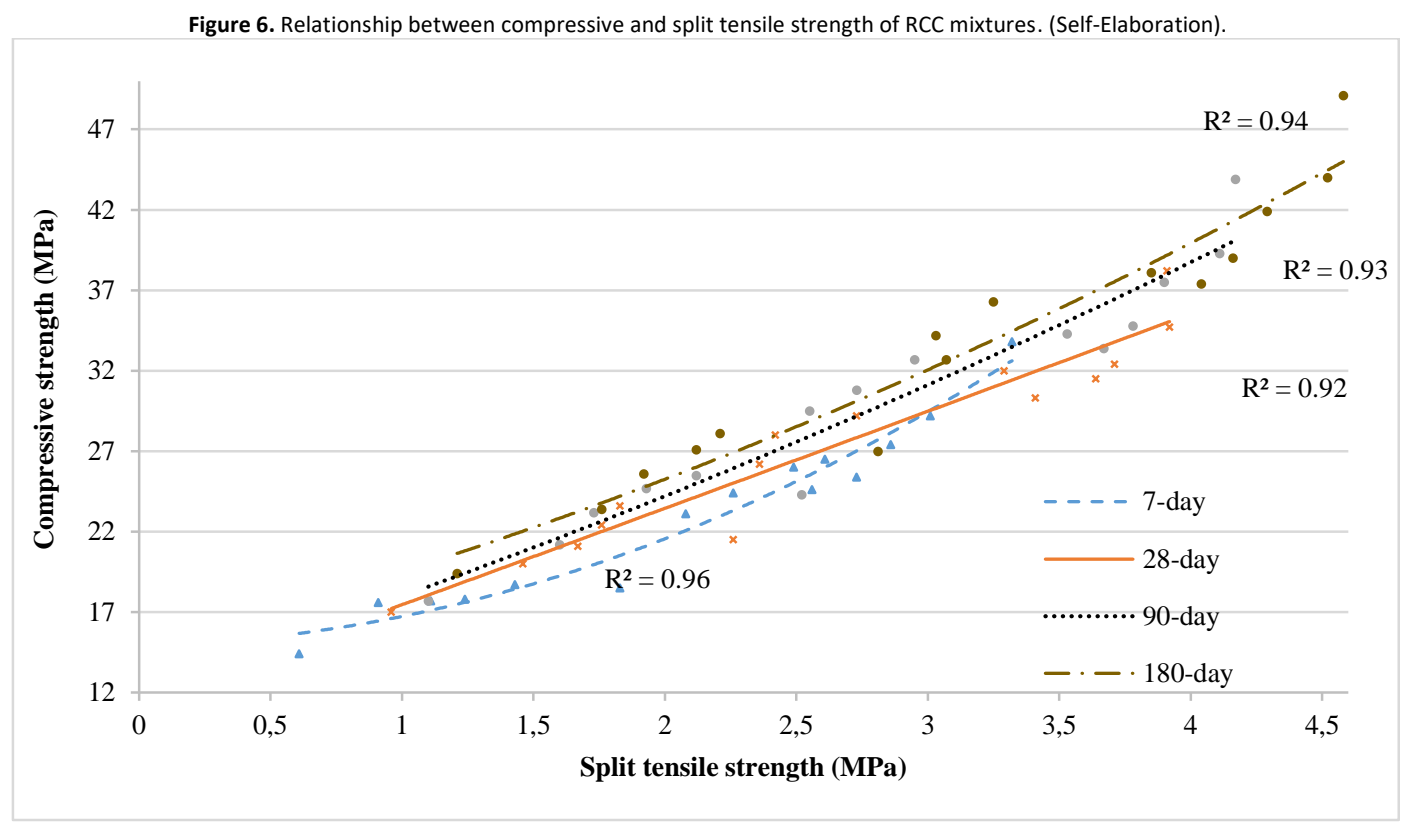




Figure 9. Comparison of the relationship between 28-day compressive - 28-day split tensile strength of RCC obtained in the present study and the study of LopezUceda et. al. (2018).

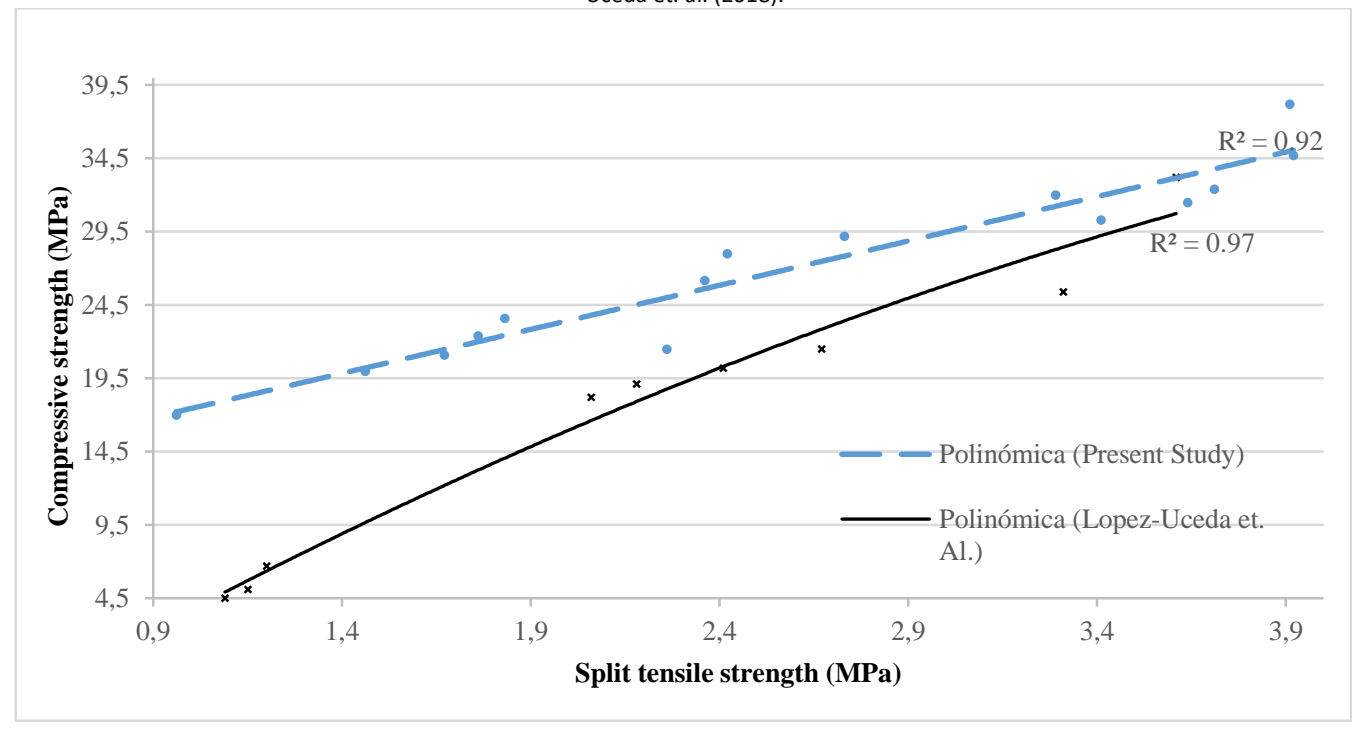

The average 28-day compressive strength /180-day compressive strength ratios for RCC mixtures containing 150, 200 and $250 \mathrm{~kg} / \mathrm{m}^{3}$ cement are around $0.84,0.81$ and 0.79 , respectively. It is possible to say that the compressive strength development beyond 28-day in RCC mixtures is more pronounced in leaner mixtures. The fact seems to be arisen, to some extent, from lower $\mathrm{w} / \mathrm{c}$ ratio of the leaner mixtures compared to the corresponding richer ones.

As it can be seen from Figure 3 increasing the cement content of the mixture from 150 to $250 \mathrm{~kg} / \mathrm{m}^{3}$ improved the 180 -day compressive strength of the control mixture by $75 \%$. The corresponding value for RCC mixtures containing 25,50 and $75 \%$ RCA was around $65 \%$, however, RCC mixture containing $100 \%$ RCA showed considerably higher strength increment (93\%). The effect of increasing cement content of the mixture from 150 to $250 \mathrm{~kg} / \mathrm{m}^{3}$ was more pronounced on the 180-day splitting tensile strength (Figure 4) than on the 180-day compressive strength. The increase in the 180-day splitting tensile strength in the control mixture upon increasing the cement content (from 150 to $250 \mathrm{~kg} / \mathrm{m}^{3}$ ) was $107 \%$. The corresponding values for $25,50,75$ and 100\% RCA-bearing mixtures were found to be $113 \%, 123 \%, 136 \%$ and $234 \%$, respectively. The improvement in either compressive or tensile strength of RCC mixtures containing 100\% RCA is interesting. This improvement may be arisen to some extent from higher W/C ratio of RCC 250/100 (0.53) compared to that of RCC 150/100 (0.48); which provides somewhat greater strength gain at later ages. Besides, it seems that the higher cement content is more beneficial in improving the ITZ upon further pozzolanic reaction arisen from the utilization of Portland composite cement. It is well-known that ITZ is the weakest link in concrete mixtures, particularly in RCA-bearing mixtures. This may result in a greater strength improvement at later ages in RCA-bearing mixtures compared to those of the control mixtures.

The 28, 90 and 180-day UPV and dynamic modulus of elasticity of RCC mixtures and the limits specified for UPV values of concrete by Whitehurst (1951) are shown in Table 5 and 6, respectively (Whitehurst, 1951). The relationship between compressive strength and UPV as well as relationship between compressive strength and dynamic modulus of elasticity of RCC mixtures are shown in Figure 10 and 11, respectively. 
Table 5. UPV values and dynamic modulus of elasticity of RCC mixtures. (Self-Elaboration).

\begin{tabular}{|c|c|c|c|c|c|c|}
\hline \multirow{2}{*}{ Mixture } & \multicolumn{3}{|c|}{ UPV $(\mathrm{km} / \mathrm{s})$} & \multicolumn{3}{|c|}{ Dynamic modulus of elasticity (GPa) } \\
\hline & 28-day & 90-day & 180-day & 28-day & 90-day & 180-day \\
\hline RCC150/0 & 3.61 & 3.68 & 3.71 & 26.21 & 27.24 & 27.69 \\
\hline RCC150/25 & 3.55 & 3.58 & 3.60 & 24.81 & 25.23 & 25.51 \\
\hline RCC150/50 & 3.5 & 3.51 & 3.52 & 23.67 & 23.81 & 23.94 \\
\hline RCC150/75 & 3.36 & 3.37 & 3.39 & 21.62 & 21.75 & 22.01 \\
\hline RCC150/100 & 3.24 & 3.26 & 3.26 & 20.06 & 20.31 & 20.31 \\
\hline RCC200/0/0 & 4.05 & 4.06 & 4.08 & 33.66 & 33.82 & 34.16 \\
\hline RCC200/25 & 3.82 & 3.83 & 3.9 & 29.43 & 29.59 & 30.68 \\
\hline RCC200/50 & 3.76 & 3.76 & 3.76 & 28.02 & 28.02 & 28.02 \\
\hline RCC200/75 & 3.60 & 3.64 & 3.67 & 25.52 & 26.09 & 26.52 \\
\hline RCC200/100 & 3.51 & 3.54 & 3.59 & 24.04 & 24.45 & 25.15 \\
\hline RCC250/0 & 4.69 & 4.69 & 4.70 & 46.40 & 46.40 & 46.60 \\
\hline RCC250/25 & 4.6 & 4.61 & 4.61 & 43.34 & 43.53 & 43.53 \\
\hline RCC250/50 & 4.49 & 4.51 & 4.52 & 40.95 & 41.32 & 41.50 \\
\hline RCC250/75 & 4.29 & 4.31 & 4.39 & 37.22 & 37.57 & 38.97 \\
\hline \multirow[t]{8}{*}{ RCC250/100 } & 4.13 & 4.16 & 4.2 & 34.11 & 34.61 & 35.28 \\
\hline & \multicolumn{4}{|c|}{ Table 6. The limit specified for concrete. (Self-Elaboration). } & & \\
\hline & & $\mathrm{UPV}(\mathrm{km} / \mathrm{s})$ & \multicolumn{2}{|c|}{ Concrete quality } & & \\
\hline & & $>4.5$ & \multicolumn{2}{|c|}{ strong } & & \\
\hline & & $3.50-4.50$ & \multirow{2}{*}{\multicolumn{2}{|c|}{$\begin{array}{c}\text { good } \\
\text { intermediate }\end{array}$}} & & \\
\hline & & $3.00-3.50$ & & & & \\
\hline & & $2.00-3.00$ & \multicolumn{2}{|c|}{ weak } & & \\
\hline & & $<2.00$ & \multicolumn{2}{|c|}{ very weak } & & \\
\hline
\end{tabular}

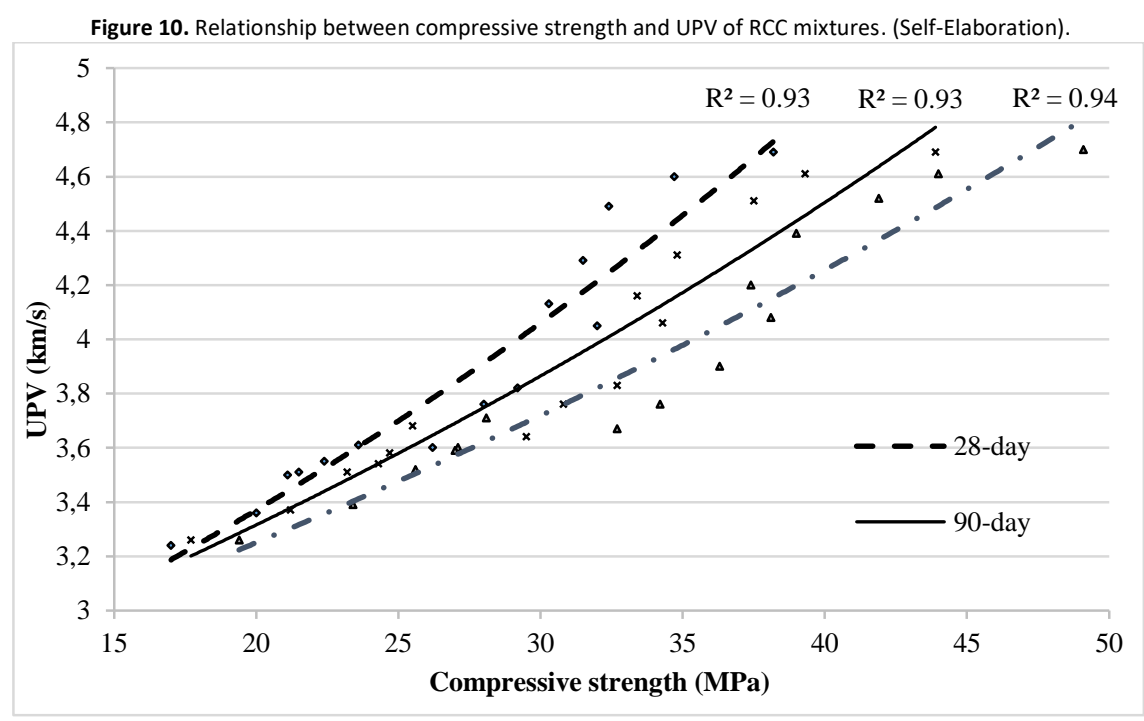


Figure 11. Compressive strength-dynamic modulus of elasticity relationship of RCC mixtures. (Self-Elaboration).

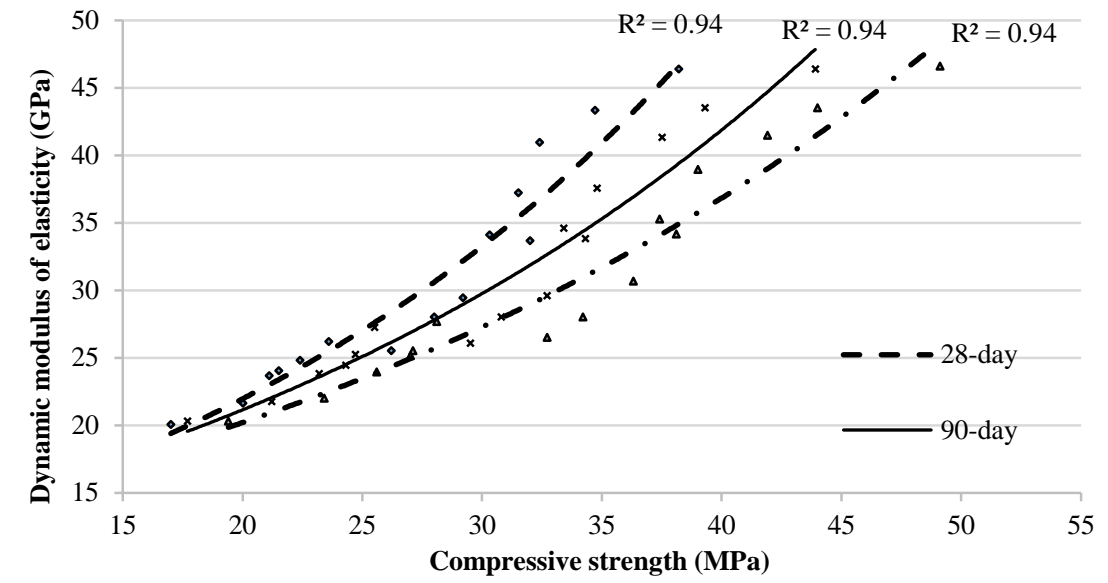

Figure 12. 95\% confidence intervals of compressive strength- UPV relationship of RCC mixtures. (Self-Elaboration).

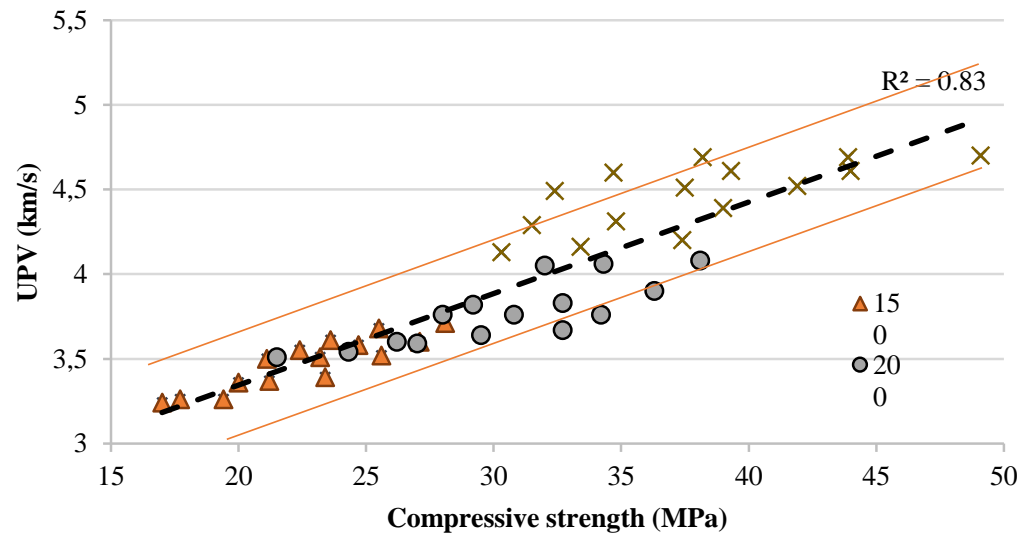

Figure 13.95\% confidence intervals of relationship between compressive strength and dynamic modulus of elasticity of RCC. (Self-Elaboration).

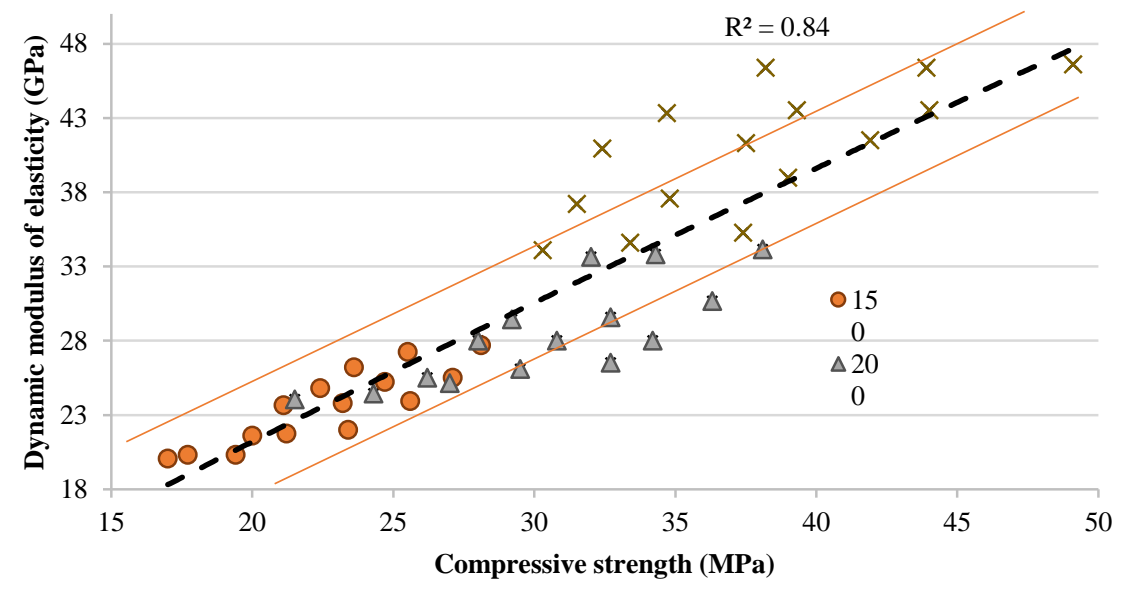


As it can be seen from the results, regardless of the cement content, the minimum UPV and dynamic modulus of elasticity values at all ages belong to the mixtures that contain 100\% RCA. Irrespective of cement content, the UPV and dynamic modulus of elasticity values of RCC mixtures reduced upon replacement of CLA with RCA. The effect increased by increasing RCA replacement level. The reduction in UPV and dynamic modulus of elasticity values upon RCA inclusion seems to be arisen from the higher w/c ratio of RCA-bearing mixtures, ITZ characteristics and the presence of porous and weak old mortar adhered on the surface of RCA particles which may cause a weaker bond strength between aggregate and new matrix compared to that of the LCA. As it can be seen from the Figure 10 and 11, good correlations, with coefficient of correlation $\left(R^{2}\right)$ values around 0.94 , were found between compressive strength, UPV and dynamic modulus of elasticity of the RCC mixtures. The $95 \%$ confidence intervals of relationship between compressive strength and dynamic modulus of elasticity of RCC mixtures are given in Figure 12 and 13.

Based on the materials used and tests applied the following conclusions can be drawn:

- Compared to these of control mixture, the optimum water content and consequently the $\mathrm{w} / \mathrm{c}$ ratio of the mixtures increased by increasing RCA substitution level. Meanwhile, a gradual reduction occurred in the unit weight of RCC mixtures upon increasing RCA replacement level.

- Replacing of $25 \%$ of crushed limestone aggregate with recycled aggregate had not a significant detrimental effect on the mechanical properties of concrete. Besides, the detrimental effect of RCC substitution reduced by increasing the cement content of the mixtures. However, increasing the amount of recycled aggregate beyond $25 \%$ decreased the mechanical properties of concrete.

- The strength, UPV and dynamic modulus of elasticity values of RCC mixtures reduced upon replacement of CLA with RCA. The effect increased by increasing RCA replacement level.

- The splitting tensile strength, UPV and dynamic modulus of elasticity developments beyond 28 days in RCC mixtures are more pronounced in richer mixtures. The fact seems to be arisen in part from higher $\mathrm{w} / \mathrm{c}$ ratio and in part from the higher pozzolanic reactions in hydrated cement paste.

Acknowledgement

The authors would like to acknowledge the financial support provided by TÜBiTAK under grant No: 213M485.

References

ACl 207.5R-99. Roller-compacted mass concrete. Reported by ACI Committee 207; 1988.

ACI Committee 544, 1988, Design Considerations for Steel Fiber Reinforced Concrete, ACI Structural Journal, 563-580.

ASTM C 597. Standard test method for pulse velocity through concrete. Annual Book of ASTM Standards. Philadelphia, PA, USA: American Society of Testing Materials; 2002.

Courard, L., Michel, F., \& Delhez, P. (2010). Use of concrete road recycled aggregates for roller compacted concrete. Construction and Building Materials, 24(3), 390-395.

Debieb, F., Courard, L., Kenai, S., \& Degeimbre, R. (2009). Roller compacted concrete with contaminated recycled aggregates. Construction and Building Materials, 23(11), 3382-3387.

EN 12390-3. Concrete testing-hardened concrete - Part 3: Compressive strength test samples. Brussels: European Standard; 2010.

EN 12390-6. Concrete: Testing-hardened concrete - Part 3: split tensile strength test samples. Brussels: European Standard; 2010.

Etxeberria, M., Vázquez, E., Marí, A., \& Barra, M. (2007). Influence of amount of recycled coarse aggregates and production process on properties of recycled aggregate concrete. Cement and Concrete Research, 37(5), 735-742.

Fakhri, M. (2016). The effect of waste rubber particles and silica fume on the mechanical properties of roller compacted concrete pavement. Journal of Cleaner Production, 129, 521-530.

Gürer, C., Akbulut, H., \& Kürklü, G. (2004, May). Recycling and re-evaluation of different building materials as a source of raw material in the construction industry. In 5th Industrial Raw Materials Symposium (Vol. 1314). 
Jalilifar, H., Sajedi, F., \& Toosi, V. R. (2020). Evaluating the durability of recycled concrete made of coarse recycled aggregate concrete containing silicafume and natural zeolite. Revista de la Construcción. Journal of Construction, 19(3), 457-473.

LaHucik, J., Dahal, S., Roesler, J., \& Amirkhanian, A. N. (2017). Mechanical properties of roller-compacted concrete with macro-fibers. Construction and Building Materials, 135, 440-446.

Lopez-Uceda, A., Agrela, F., Cabrera, M., Ayuso, J., \& López, M. (2018). Mechanical performance of roller compacted concrete with recycled concrete aggregates. Road Materials and Pavement Design, 19(1), 36-55.

Meddah, A., Beddar, M., \& Bali, A. (2014). Use of shredded rubber tire aggregates for roller compacted concrete pavement. Journal of Cleaner Production, 72, 187-192.

Modarres, A., \& Hosseini, Z. (2014). Mechanical properties of roller compacted concrete containing rice husk ash with original and recycled asphalt pavement material. Materials and Design, 64, 227-236.

Muscalu, M. T., \& Andrei, R. (2011). Use of recycled aggregates in rigid pavement construction. Buletinul Institutului Politehnic din lasi. Sectia Constructii, Arhitectura, 57(2), 69.

Neville A. M. Concrete technology. 2nd ed. UK: Longman; 2010.

Paul, S. C., \& Van Zijl, G. P. A. G. (2013). Mechanical and durability properties of recycled concrete aggregate for normal strength structural concrete. International Journal of Sustainable Construction Engineering and Technology, 4(1), 89-103.

Peng, G. F., Huang, Y. Z., Wang, H. S., Zhang, J. F., \& Liu, Q. B. (2013). Mechanical properties of recycled aggregate concrete at low and high water/binder ratios. Advances in Materials Science and Engineering, 2013.

Philleo, R. E. (1955, January). Comparison of results of three methods for determining Young's modulus of elasticity of concrete. In Journal Proceedings (Vol. 51, No. 1, pp. 461-470).

Rao, M. C., Bhattacharyya, S. K., \& Barai, S. V. (2011). Behaviour of recycled aggregate concrete under drop weight impact load. Construction and Building Materials, 25(1), 69-80.

Settari, C., Debieb, F., Kadri, E. H., \& Boukendakdji, O. (2015). Assessing the effects of recycled asphalt pavement materials on the performance of roller compacted concrete. Construction and Building Materials, 101, 617-621.

Sonawane, T. R., \& Pimplikar, S. S. (2013). Use of recycled aggregate concrete. IOSR Journal of Mechanical and Civil Engineering, 52, 59.

Whitehurst, E. A. (1951, February). Soniscope tests concrete structures. In Journal Proceedings (Vol. 47, No. 2, pp. 433-444). 